\title{
Grafica y Accion Directa \\ Cinco horizontes de circulación en la producción del Taller 4 Rojo
}

\author{
Equipo TranshisTor(ia) ${ }^{1}$
}

\begin{abstract}
Resumen
En la investigación "Rojo y más Rojo. Taller 4 Rojo; producción gráfica y acción directa" (2009-2012), de la que derivó una curaduría y una publicación homónimas (2015), prestamos especial atención a conformar un espectro amplio sobre la producción visual desarrollada por el Grupo Taller 4 Rojo durante la década de 1970, parcialmente abordada y descrita por diferentes trabajos del campo de la Historia del arte en Colombia; nos propusimos identificar fuentes y prácticas creativas que caracterizaron la producción de esta plataforma de creación colectiva así como sus horizontes de circulación. Este artículo es una lectura parcial sobre dicha investigación con la que esperamos señalar cinco prácticas creativas y campos de circulación que con mayor claridad manifiestan el horizonte de acción política que el Grupo Taller 4 Rojo se propuso, donde la combinación de temas, procesos creativos y prácticas de circulación sustentaron tales intereses.
\end{abstract}

\section{Palabras clave}

Taller 4 Rojo; producción gráfica; prácticas creativas; campos de circulación

\begin{abstract}
In the research "Rojo y más Rojo. Taller 4 Rojo; producción gráfica y acción directa" (2009-2012), which led to a curatorship and a homonyms publication (2015), we paid special attention to broadly outline the visual production developed by the Group Taller 4 Rojo during the 1970s, which have been partially addressed and described by different studies in the field of art history in Colombia; we set out to identify sources and creative practices that characterized the production of this platform of collective creation as well to discuss their circulation. This article is a partial result of this research, from which we tried to point out five creative practices and fields of circulation that demonstrate the horizon of political action that Group Taller 4 Rojo proposed for itself, and was sustained by a combination of subjects, creative processes and practices.
\end{abstract}

\section{Key-words}

Group Taller 4 Rojo; graphic production; creative practices; fields of circulation

\footnotetext{
${ }^{1}$ Conformado desde 2008 pelos Maria Sol Barón y Camilo Ordóñez, profesores de la Javeriana y la Distrital, TransHistor(ia) es un equipo dedicado a desarrollar proyectos de investigación y creación en torno a problemas relacionados con la Historia del Arte Colombiano y Latinoamericano, y encaminados a implementar propuestas curatoriales que involucren diversos campos relacionados con la cultura visual y la museografía como propuesta creativa. 


\section{Introducción}

La producción y circulación del trabajo creativo realizado por el colectivo de artistas denominado Taller 4 Rojo no ha resultado invisible en relatos y estudios aportados por la Historia del arte en Colombia, pero su resultado ha sido parcial. Desde la época en que esta plataforma y equipo de trabajo artístico fueron conformados, su trabajo prontamente resultó registrado en proyectos editoriales que aún hoy resultan necesarios para la comprensión de arte colombiano; es el caso de la Historia del Arte Colombiano, enciclopedia editada originalmente por Salvat en 1975, donde se incluyó un fascículocapitular firmado por Germán Rubiano como "La Figuración política" (1983: 1563-1584) $)^{2}$ dedicado -entre otras manifestaciones- a la producción creativa sostenida desde este taller.

Rubiano se ocupó en describir el entorno profesional y académico de algunos miembros del taller, presentar algunos temas abordados (se incluyeron reproducciones de las siete fotoserigrafías que hacen parte de la colección del Museo de Arte de la Universidad Nacional de Colombia del que Rubiano fue su primer director), señalar el aporte técnico- creativo al campo de la gráfica colombiana, y mencionar algunos horizontes de acción política que interesaban al grupo, particularmente el carácter testimonial 0 de denuncia manifiesto en algunos trabajos, el acompañamiento a movimientos sociales y su participación en la producción visual de algunas publicaciones con declaradas inclinaciones ideológicas de izquierda como la revista Alternativa. En resumen, se trata de una buena síntesis sobre la trayectoria del grupo que, a su vez, deja campos abiertos de reflexión e investigación para el desarrollo de otras investigaciones que aportarían a una comprensión compleja o más detallada sobre la plataforma y proceso creativo -artístico y político- que implicó el Taller 4 Rojo.

En efecto, al capítulo aportado por Rubiano han seguido otras publicaciones que, paulatinamente, abordan diferentes elementos y valoraciones sobre la trayectoria, periodización y contextualización del grupo. En este orden de ideas, Clemencia Arango (2002) y Alejandro Gamboa (2011) han prestado especial interés en sus investigaciones a establecer diferentes "etapas" del grupo a partir de su establecimiento, conformación e integrantes. En términos generales, varios de estos relatos coinciden en describir la conformación consolidada del colectivo con la participación de Diego Arango (1942), Carlos Granada (1933), Umberto Giangrandi (1942), Fabio Mora (1944), Rabio Rodríguez Amaya (1950) y Nirma Zarate (1936); sin embargo, los testimonios

2 Esta publicación no sólo corresponde a la primera historia del arte colombiano de gran envergadura e ilustrada profusamente en Colombia, sino que además se dirigió a un público no especializado, evidente por su lenguaje y estilo narrativo, didáctico y sencillo, además por la estrategia comercial y de distribución de su primera edición: entre julio de 1975 y el primer semestre de 1977 circularon semanalmente (cada jueves un nuevo número) ochenta y cuatro fascículos con un valor de veinticinco pesos que eran vendidos en almacenes de cadena. Ver: Barón M.S. y Ordóñez C., Plataformas de producción para la historia del arte colombiana, 2015. 
de la mayoría de estos artistas, así como algunos de estos estudios dedicados al Taller 4 Rojo (Arango, 2002 y Gamboa, 2011) insisten en aclarar su entorno de creación colectiva con la participación de intelectuales colombianos como Jorge Villegas, Germán Rojas, Bernardo García entre otros, lo que permite imaginar un ambiente de discusión y debate colectivos semejante al de algunas organizaciones sociales, y afín al esquema de producción compartida que exige un taller de grabado.

De modo que la "alineación" de miembros participantes en el taller resulta sinuosa y en cierta medida explica la necesidad que otros autores han tenido para comprender este proceso histórico de acuerdo a fases y participantes. En el libro Rojo y más Rojo (2015), decidimos comprender este proceso complejo como un "campo circundante del Taller 4 Rojo", un "momento" en el que coincidieron actores, grupos, estrategias, prácticas artísticas y políticas, pero al cabo, una determinación afín con términos que la Historia del arte y la nomenclatura del grabado ha usado para nombrar algunos escenarios de producción artística (Vives, 2003). Consecuentemente, prestamos mucha atención a identificar las declaraciones y los documentos que indicaban cómo el colectivo se autodefinió en cuanto a sus integrantes en diferentes instancias 0 momentos $^{3}$. Indudablemente esta revisión nos permitió imaginar la complejidad y entusiasmo (político y artístico) que implicó la plataforma creativa del grupo para comprenderle como proceso histórico. Este interés por seguir o comprender la conformación del grupo en sí, era importante para poder comprender aspectos de la creación colectiva del Taller 4 Rojo. Hasta el momento del inicio de nuestra investigación el conocimiento sobre la producción visual concreta, amplia y diversa aportada por el grupo resultaba reducida, y estaba limitada a reproducciones como las de la enciclopedia editada por Salvat o algunos catálogos de exposiciones, mientras que los horizontes de circulación ajenos al campo convencional del arte eran insuficientes, pero determinantes para comprender la acción política presupuestada por el grupo.

En 2010, gracias al IV Premio de Curaduría Histórica de la Fundación Gilberto Alzate Avendaño en Bogotá, emprendimos una investigación con la que buscábamos comprender la trayectoria del Taller 4 Rojo de acuerdo al sustento aportado por su producción y circulación visual concreta, lo que implicó identificar un panorama de imágenes mayor al comúnmente comprendido, el cual, una vez conformado, fue útil como insumo para emprender una reflexión

\footnotetext{
3 Por ejemplo, en 1970 Arango, Zárate y Mora conformaron un "Taller 4 Rojo" que en su papelería manifestaba la prestación de servicios gráficos. Dos años más tarde, con la participación de los seis artistas mencionados un nuevo equipo, denominado "Grupo Taller 4 Rojo", se estableció ocupando los talleres y equipos del primero y del taller que Giangrandi, de origen italiano, había establecido en Bogotá desde 1968; a partir de 1974, el colectivo conservó la denominación de 1972 pero aclaraba su integración, exclusivamente conformada por Granada, Giangrandi y Rodríguez. Pudimos identificar estos datos confrontando papelerías sellos, membretes, firmas, créditos y otros elementos recurrentes en la producción gráfica a los que tuvimos acceso en archivos particulares. Ver Rojo y más Rojo (Barón y Ordóñez, 2015: 126-133). 
sobre procesos, fuentes o estrategias creativas invertidas en la producción de estas imágenes, determinante para indagar sobre campos de circulación de estas imágenes en concordancia con los horizontes de acción política que el grupo asumió. De modo que la comprensión creativa de la imágenes y sus estrategias o estructuras empleadas para circular dieran cuenta concreta, como un índice, del trabajo político propuesto por el Taller 4 Rojo en su acompañamiento a movimientos sociales y el emprendimiento de acciones directas que, en aquel contexto, se encaminaban a participar en la transformación de la realidad. Para cumplir este propósito de la investigación identificamos catálogos, revisamos archivos personales e institucionales, confrontamos documentación editorial y con ello elaboramos un catálogo amplio sobre la producción del "campo circundante del Taller 4 Rojo", y a su vez realizamos entrevistas a los artistas y otros actores participantes del horizonte descrito por el taller. En este artículo presentamos una lectura puntual sobre cinco prácticas y estrategias de circulación no restringidas al campo convencional del arte, que dan cuenta de la comunión entre creación y circulación con que el grupo se propuso concretar algunos horizontes de acción política.

\section{Operaciones creativas de apropiación y para la contrainformación}

La primera plataforma creativa del Taller 4 Rojo (definido de este modo en 1970) implicó un taller establecido por Diego Arango y Nirma Zárate junto a Jorge Mora en el barrio La Candelaria, en Bogotá, y destinado a la producción artística (individual y colectiva) como a la prestación de servicios de producción gráfica. Allí se pusieron en práctica los conocimientos sobre fotomontaje y fotoserigrafía aprendidos por Zárate unos meses atrás durante un corto viaje de estudios a Londres en la Royal Academy of Arts; conocimientos que también los socializó en la Escuela de Artes de la Universidad de los Andes donde ella compartió escenario como profesora en los talleres de grabado que Umberto Giangrandi había organizado junto a otros profesores en 1968.

Al tiempo, este momento también suscitó discusiones con artistas e intelectuales que (gracias a la amistad, afinidad política y proximidad urbana al local del taller) estimularon una producción visual donde la apropiación de fuentes fotográficas, transferidas y mediadas en el proceso creativo destinado a la producción de estampas realizadas en fotoserigrafía, propició su comprensión como matrices que, en tanto portadoras de información, podrían ser reformuladas para sostener contenidos destinados a denunciar y contrainformar sobre asuntos derivados de la realidad social ${ }^{4}$, y antagónicos de la representación de la realidad operada por la prensa y la propaganda de Estado, asunto que nos interesa resaltar en este apartado en la medida en que

\footnotetext{
${ }^{4}$ Este tipo de operaciones creativas ya se había manifestado en la producción artística individual de Umberto Giangrandi y, en cierto momento caracterizó el trabajo individual de Zárate. La producción del taller de Zárate y Arango, como la de Giangrandi utilizaba la apropiación de fuentes fotográficas que eran comprendidas como plataformas o móviles de información. 
desde este taller se diseñaron algunas publicaciones independientes con un claro carácter contrainformativo ${ }^{5}$.

Muy pronto, el escenario laboral de Jorge Mora, quien trabajaba en el equipo de diseño editorial del Departamento Nacional de Estadística (DANE), señaló un campo de información técnica susceptible de ser intervenido. Hasta hoy, una de las misiones del DANE consiste en producir, sistematizar y divulgar información estadística requerida por el estado colombiano para sustentar el desarrollo de políticas y líneas de acción del aparato estatal; para entonces la divulgación convencional de esta información era vertida en cartillas y boletines que, de acuerdo a la práctica estadística, requerían de una diagramación y producción infográfica que dinamizara los datos; así las cosas un equipo de creativos -como Mora- en interlocución con otros intelectuales -como Bernardo García y Jorge Villegas, quienes también trabajaban en el DANEdio lugar a prácticas de fotomontaje y factografía afines a las que se estaban realizando en la plataforma del Taller 4 Rojo; de este modo los datos oficiales comisionados por el estado colombiano eran ilustrados y graficados con composiciones visuales que, sin desmentir la información producida por el DANE, generaban una intensión editorial sobre la lectura inmediata de los datos. Caricaturas, fotomontajes, titulares e imágenes de la prensa local eran reorganizados para declarar mensajes que, notoriamente, contrastaban la información al interior de las mismas cartillas; se generaba así una lectura crítica e irónica sobre la realidad social y económica colombianas desde la propia institución oficial de estadística. Por ejemplo, en el boletín sobre "Sistema de salud en Colombia" se encuentran unas imágenes que retratan el amor de una madre y su bebe en perfecta armonía y sanos, junto a otras que, literalmente dispuestas al revés, muestran niños desnutridos en medio de un ambiente de pobreza y precariedad.

Una operación semejante fue emprendida en el "campo circundante del Taller 4 Rojo" para producir dos publicaciones con un claro interés testimonial y contrainformativo destinado a controvertir la manera en que la prensa, la publicidad y la propaganda estatal registraban la historia reciente del país: "Planas o la destrucción de la nación indígena" (1970) y "El papa visita Colombia"(1971). Ambas publicaciones denunciaban hechos sucedidos recientemente en Colombia, articulando información e imágenes confiscadas, en su mayoría, de la prensa escrita. Planas descubría la complicidad del Estado colombiano en el acoso y abusos cometidos en el Departamento del Meta por la fuerza pública contra los comunidad indígena Guahibo sobre sus

\footnotetext{
${ }^{5}$ Estas operaciones se manifestaron en la serie de estampas realizadas por Nirma Zárate destinadas a documentar y denunciar la mala suerte de la niñez abandonada o en estado de indigencia en Bogotá, pues la mayor parte de las imágenes empleadas en estas piezas provienen de reportería gráfica y propaganda (particular o estatal) originalmente publicada en prensa local. Ahora bien, el campo de circulación de las estampas realizadas por Zarate correspondió a aun escenario convencional de circulación en el campo del arte: salones, premios, y bienales.
} 
territorios en 1970. Aquellos indígenas que no murieron, fueron objeto de tortura, o fueron desplazados; tan grave fue la situación, que en el Congreso de la República se denunciaron por primera vez los exterminios indígenas en Colombia. Al interior del impreso los autores alternaron titulares e imágenes de prensa que en su ordenación hacen explícita la agresión de los militares y la desigualdad de las fuerzas del conflicto. El contenido se complejiza y se enriquece al incluir trascripciones de entrevistas o testimonios, algunas imágenes escasamente divulgadas y otros documentos de carácter estadístico e histórico. La otra publicación, El papa visita a Colombia, elaborada con las mismas estrategias creativas, plantea un relato dividido en tres momentos: el primero parodia la propaganda y autopromoción que varias empresas e industrias locales desataron con la visita del Papa Juan Pablo VI, máximo jerarca de la Iglesia Católica; enseguida, se descubren las controversias desatadas por la manera en que se ocultó la indigencia y la crisis de desnutrición infantil durante la coyuntural visita; y por último se plantea una mirada a la faceta más radical del catolicismo cristiano, en la que se equipara el carácter revolucionario de Jesucristo, Ernesto "Che" Guevara y el cura guerrillero Camilo Torres. Ambas publicaciones incluyen referencias sobre el origen de las fuentes al punto de calificar los periódicos y revistas de origen como "colaboradores"; ambas fueron impresas en offset, según parece, bajo la coordinación editorial de Oveja Negra fundada en 1969 por José Vicente Kataraín, quien cuatro años mas tarde participó en otro escenario creativo del Taller 4 Rojo, la revista Alternativa, una publicación que buscó la convergencia de varias posturas de la izquierda colombiana.

En 1974, tras el establecimiento de Alternativa, las operaciones creativas del Taller 4 Rojo centradas en la apropiación de fuentes visuales y la confección de imágenes dispuestas a contrainformar resultaron recurrentes en la diagramación de la revista, particularmente durante los primeros números hasta que tanto el grupo como la revista tuvieron fracciones internas, según nuestra pesquisa, hacia fines de 1974. La producción aportada por el grupo a la revista fue tal que esta producción visual puede ser comprendida como una expresión editorial de la revista. Según Álvaro Medina, quien participó en la diagramación de un par de números de esta publicación, el acceso a fuentes fotográficas del diario El Tiempo era total y fue propiciado gracias a la cercanía que Enrique Santos (uno de los fundadores de Alternativa) tenía con el diario capitalino como miembro de la familia propietaria de aquel periódico. Ahora bien, la producción visual que caracterizó a la revista Alternativa merece especial atención y es parcialmente abordada en Rojo y más Rojo (2015). 


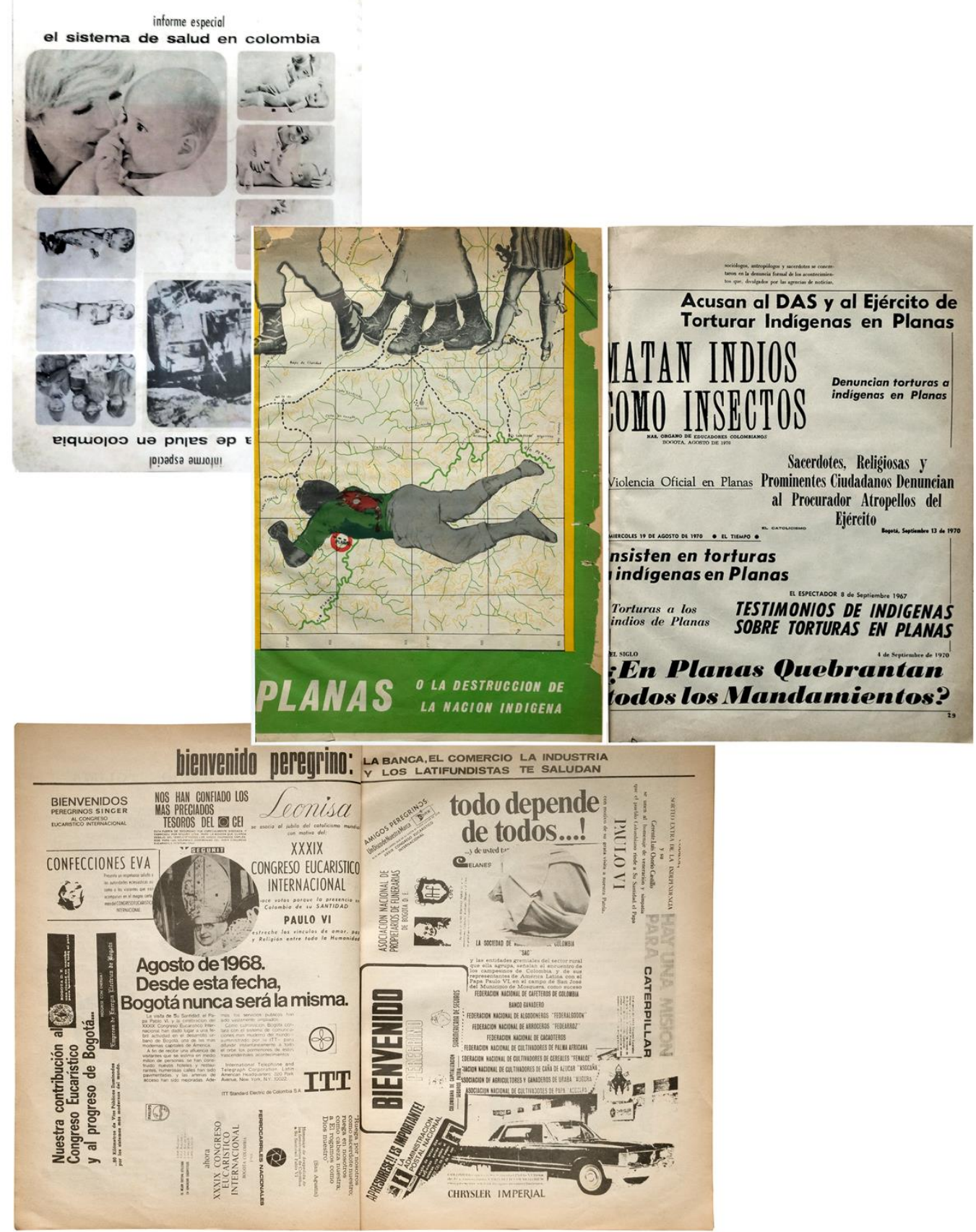

Fig. 1. Páginas interiores de publicación realizada por el DANE (Ca. 1970), portada y página interior de Planas o la destrucción de la nación indígena (1970), y páginas interiores de El papa visita Colombia (Ca. 1971)

De modo que la apropiación de imágenes y la conversión de sus contenidos a través de procesos de montaje y factografía (Buchloch, 2004) implicaron un horizonte creativo común en la plataforma creativa del Taller 4 Rojo y fue recurrente en varios escenarios creativos abordados por el grupo.

\footnotetext{
${ }^{6}$ Todas las fotografías fueron tomadas por Camilo Ordóñez Robayo/Equipo TransHisTor(ia).
} 


\section{2. "Redes, acuerdos, declaraciones, acciones"}

El horizonte de circulación dispuesto para la producción artística emprendida por los miembros del Taller 4 Rojo desde de su conformación como colectivo describe un escenario de eventos, exposiciones, bienales y premios convencionales del campo del arte a nivel nacional (como el Salón Nacional de Artistas) y regional (como la Bienal de San Juan de Puerto Rico). Sin embargo, los temas y lenguajes emprendidos individualmente por algunos de los miembros que conformarían el grupo dan cuenta de un horizonte de circulación que paulatinamente se desmarcaría del campo del arte y se orientaría a escenarios de producción, intercambio y circulación donde las prácticas artísticas y las prácticas políticas entraban en franca comunión.

Un claro ejemplo de este tránsito es el rol que el tema de la invasión a Vietnam, cobró en algunos miembros del grupo, primero en Umberto Giangrandi y en el trabajo mancomunado de Zárate y Arango. El primer caso corresponde a un dibujo que sirvió para la elaboración de un cartel que manifiesta el desacuerdo frente a las intervenciones norteamericanas en Asia. El segundo caso, compuesto como una trilogía resuelta en serigrafía circuló en la Bienal de Venecia de 1972, pero poco después lo hizo en el Primer Encuentro de Artistas Latinoamericanos en La Habana, Cuba, como lo demuestran los registros fotográficos de la exposición donde se pueden ver las tres estampas dispuestas en mamparas que articulaban la el espacio de sala. El tema de la intervención norteamericana en Vietnam fue un tema común en la producción gráfica cubana, particularmente en los carteles elaborados para la Organización para la Solidaridad con Países de África, Asia y América Latina (OSPAAAL). Muchos de estos carteles se confeccionaron con mensajes e imágenes explícitamente destinadas a divulgar y apoyar la resistencia popular vietnamita y la resistencia popular de otras naciones de la región y África donde se manifestaron intervenciones coloniales por parte de los Estados Unidos de América y otras naciones del primer mundo (Bermúdez, 2000). En este orden de ideas el dibujo de Giangrandi y su destino al incorporarlo en un cartel destinado a divulgar la "Exposición-subasta" organizada por el Consejo Colombiano de la Paz resulta sincrónico con el tipo de producción gráfica que acompañó el horizonte político de la OSPAAAL; y, al tiempo, la popular trilogía de fotoserigrafías realizadas por Diego Arango y Nirma Zárate compuestas por Agresión del imperialismo a los pueblos, A la agresión del imperialismo, guerra popular, y Vietnam nos señala el camino, aunque no circuló en el volumen de aquellos carteles impresos en offset para OSPAAAL, y aunque no participaron de ninguna acción política concreta (como sí el dibujo de Giangrandi empleado en el cartel), manifiestan una afinidad temática, al asumir el tema de la intervención en Vietnam y la resistencia popular como un horizonte de lucha internacionalista, y la comprensión de la imagen como un vehículos de contenidos volcados en el lenguaje y posibilidades de circulación de la estampa. Incluso, el catálogo de la exposición de arte realizada con motivo del 
encuentro sostenido en 1972 incluye un pronunciamiento de solidaridad con el pueblo de Vietnam.

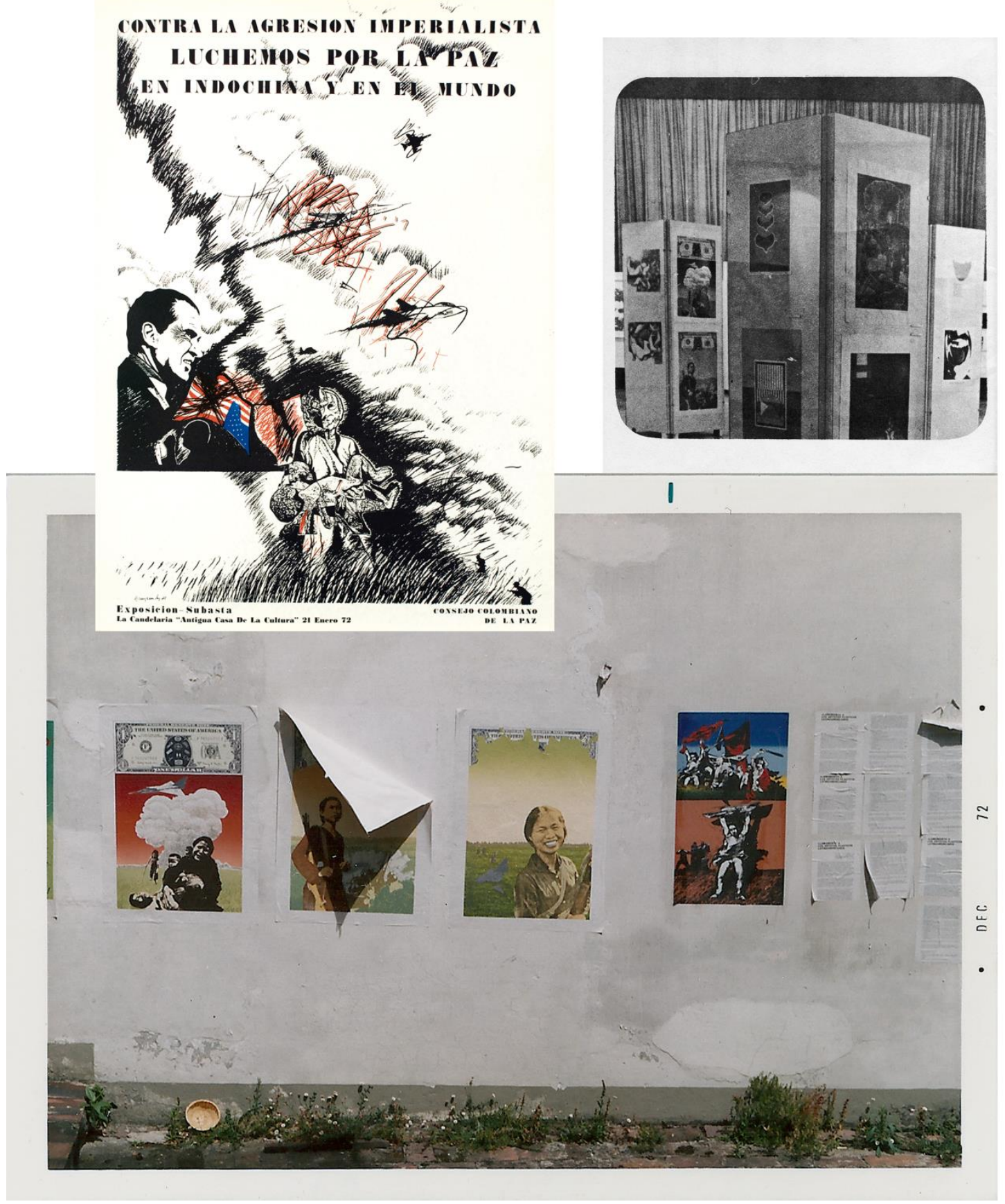

Fig. 2. Cartel realizado por Umberto Giangrandi en solidaridad con el pueblo de Vietnam (1971), página interior del Boletín Artes Plásticas de Casa de las Américas con un registro de la exposición realizada en el Encuentro de Plástica Latinoamericana en La Habana (1972), y registro de la intervención realizada por el Grupo Taller 4 Rojo en espacios públicos de la Universidad de los Andes (1972) donde se incluyó la trilogía dedicada a la resistencia vietnamita. 
Un año después, la participación el grupo en la segunda versión del encuentro en 1973 fue preparada en sintonía con algunos de los acuerdos de artistas pactados en 1972 Primer Encuentro de Artistas Latinoamericanos en La Habana, Cuba: tras el establecimiento de grupos de trabajo en cada país, de hecho, la papelería del Grupo Taller 4 Rojo, presumiblemente elaborada después del primer encuentro acoge el término "Grupo de trabajo - Colombia"; consecuentemente, algunos acuerdos sostenidos en La Habana se manifestaron en acciones de circulación y formación emprendidas por el grupo durante 1973 y años posteriores. Así corresponde a la decisión de los artistas del Grupo Taller 4 Rojo de rechazar la participación en eventos convencionales del campo del arte patrocinados con capitales de empresa, industria privada 0 filial de compañías norteamericanas. Tal posición se concreto en el rechazo del taller a la segunda versión de la Bienal de Artes Gráficas de Cali (1973) organizada en el Museo la Tertulia de Cali y patrocinada por Propal y otras compañías comprometidas en la explotación de la industria papelera en el Valle del Cauca, lo cual incluyó la elaboración de comunicados sobre esta situación (Anónimo, ca. 1973). Otra expresión de aquellos acuerdos fue el establecimiento de escuelas populares de formación artística que el Grupo Taller 4 Rojo asumió con la creación de una escuela de formación y el emprendimiento de talleres dirigidos a trabajadores de diferentes sectores sindicales colombianos, una práctica que acompañó la acción del grupo en lo sucesivo. Al mismo tiempo, según las tentativas planteadas en Cuba, el grupo realizó exposiciones en espacios públicos y en entornos de concentración popular obrera, indígena y estudiantil, y, en esos mismos escenarios divulgó el "Llamamiento a los artistas plásticos latinoamericanos" (Casa de las Américas, 1972), un manifiesto firmado en Cuba donde se expresan algunas de estas posiciones y líneas de acción.

Existe documentación fotográfica de, al menos, una exposición realizada en 1972 con estas características en el espacio abierto aledaño a la Escuela de Bellas Artes de la Universidad de los Andes, junto al Edificio Richard. Allí se colocaron un conjunto de serigrafías elaboradas individual y colectivamente por el Taller 4 Rojo, referidas a la represión que sufrió el movimiento estudiantil en las movilizaciones que tuvieron lugar durante el primer trimestre de 1971 en diferentes ciudades de Colombia. En la fotografía se observa cómo junto a las estampas se ubicó una reproducción del "Llamamiento a los artistas plásticos latinoamericanos" con lo cual se declaraba la intención de la exhibición abierta, fuera los museos o eventos especializados del arte, con el objetivo de interpelar directamente a la comunidad universitaria "uniandina" sobre un suceso reciente que afectaba a su institución, cuando las directivas decidieron congelar las actividades académicas durante al menos un semestre y declararon el cierre de la Escuela de Bellas Artes. 


\section{Imágenes en tránsito. Movilización y representación}

Una buena parte de la producción abordada por el grupo estuvo dirigida a la recuperación y circulación de imágenes que activaran la memoria sobre líderes sociales colombianos ${ }^{7}$. En ese repertorio visual se encuentran figuras históricas como María Cano, líder del movimiento obrero durante la tercera década del siglo XX y cofundadora del Partido Socialista Revolucionario en 1926, también se hicieron visibles otros mártires de la lucha social contemporáneos al proceso del taller como Gustavo Mejía, líder indígena del Departamento del Cauca, asesinado en 1974 y Luis Carlos Cárdenas, presidente de Sintradepartamento, organización abanderada del sindicalismo independiente, quien fue asesinado por fuerzas del Estado en 1973. Como se puede deducir, éste tipo de estampas tuvo una función conmemorativa sobre representantes de la lucha social ${ }^{8}$ que apuntaba a interpelar, tanto temática como técnicamente, a unos públicos que se extendían más allá del campo artístico, es decir, más allá de los tradicionales y especializados. Cada una de estas estampas tuvo diferentes campos de circulación y diferentes públicosobjetivos de acuerdo a los dispositivos de circulación y a las formas de apropiación que terceros hicieron de estas imágenes.

El cartel de María Cano (Arango y Zárate, 1970), por ejemplo, presenta a un retrato de medio cuerpo de la líder obrera con un vestido y un sombrero a la moda de los años veinte. Un fondo naranja resalta su figura y delante de ella se encuentra una multitud de jóvenes que resultan ser contemporáneos de la obra: se trata de un cartel que muestra a Cano como figura tutelar del movimiento social contemporáneo. Por último, en una suerte de marco impreso se observa repetido el nombre de la líder, y en la zona inferior derecha una flor roja permite identificar el seudónimo con que fue conocida Cano, y que da título a la obra: La flor roja del trabajo. La técnica en que fue realizado -offsetpermitió una disposición de circulación masiva, ya que la estampa, tal como Arango ha declarado en algunas entrevistas, circuló ampliamente a través de Voz del pueblo, órgano de difusión del Partido Comunista Colombiano. Sin embargo, este cartel también fue presentado en la Primera Bienal de Artes Gráficas de Cali en 1971, lo cual da cuenta de la participación en espacios convencionales del arte que los integrantes del grupo mantuvieron inicialmente. ${ }^{9}$

\footnotetext{
${ }^{7}$ Propósito que coincidía con la labor emprendida por el investigador social Orlando Fals Borda y la Fundación La Rosca de rescatar a través de la elaboración de cartillas gráficas las historias de lucha de campesinos e indígenas, para que los luchadores campesinos contemporáneos se apropiaran de estas historias y sus protagonistas (Rojas, 2015).

${ }^{8}$ Aunque no los referiremos en este artículo, entre este repertorio se encuentran también otros líderes como el indígena Manuel Quintín Lame, contemporáneo a María Cano, y Camilo Torres, sacerdote y líder del movimiento político Frente Unido.

${ }^{9}$ En la investigación y en las decisiones curatoriales en torno al Taller 4 Rojo reconsideramos estas circunstancias cuando decidimos elaborar una edición facsimilar del cartel de María Cano para su distribución gratuita durante la segunda versión de la exposición realizada en el Museo de Arte Moderno de Medellín en 2013.
} 

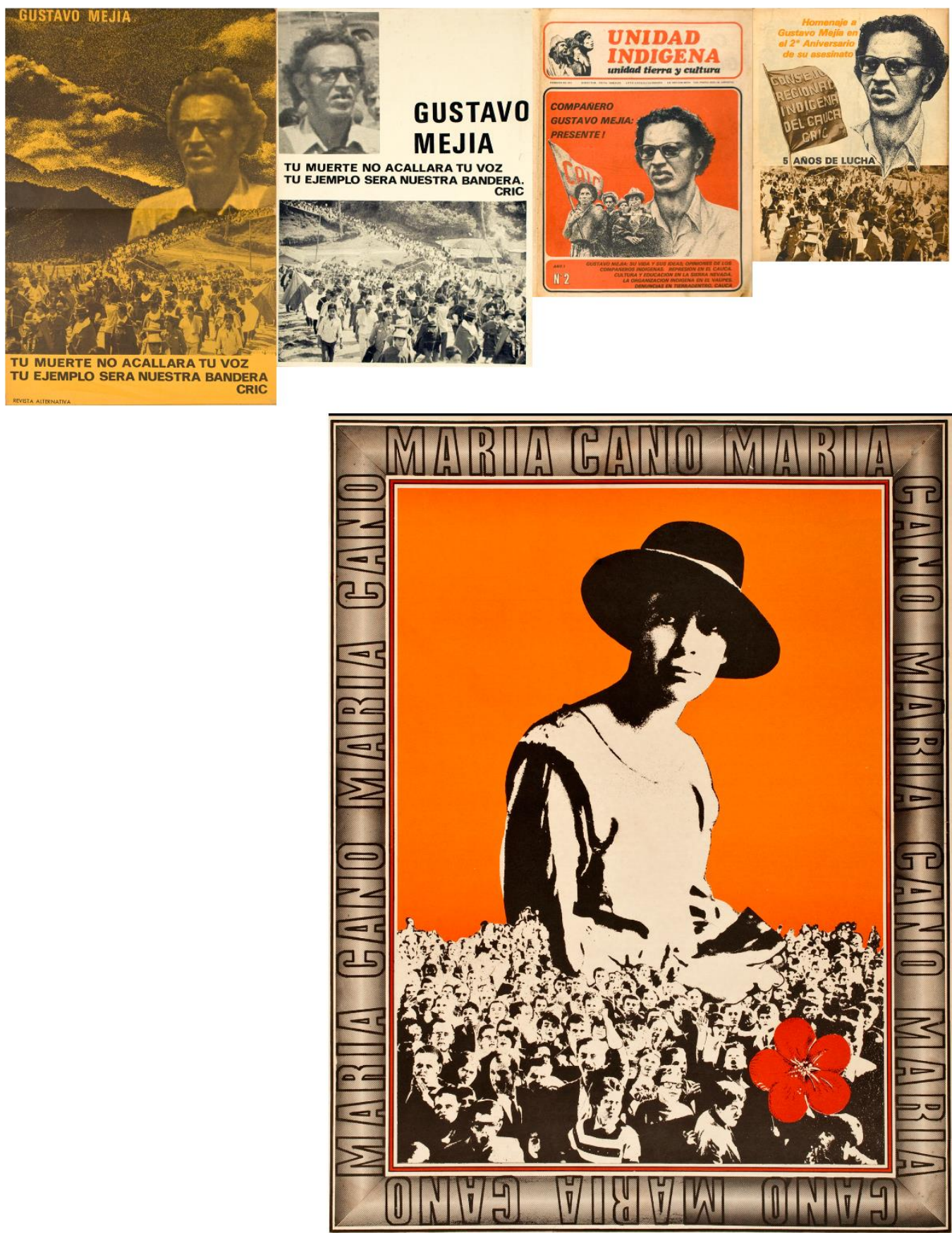

Fig. 3. Carteles sobre Gustavo Mejía, entre ellos los que circularon en la Revista Alternativa y en Unidad Indígena, y cartel La flor roja del trabajo (Diego Arango y Nirma Zárate / Grupo Taller 4 Rojo. 1970, 100 x $70 \mathrm{~cm}$ )

De otro lado, el cartel de Gustavo Mejía, líder del Consejo Regional Indígena del Cauca (CRIC) asesinado en 1974, presenta su rostro como fondo de las movilizaciones, de manera semejante a como figura la imagen de María Cano tras el movimiento obrero. Su figura aparece como un busto que confluye entre las cadenas montañosas del Departamento del Cauca en la zona andina

VIS Vol.15, n²/julho-dezembro de 2016 Brasília
ISSN-1518-5494 ISSN (versão eletrônica):2447-2484 
colombiana, y ante una amplia movilización indígena que se desenvuelve por ese paisaje sinuoso. Originalmente, el cartel con la imagen de Mejía se incluyó en un número de la Revista Alternativa, como era usual en esta publicación, lo cual facilitó que este material se difundiera entre activistas indígenas y que por lo mismo el afiche se incorporara en acciones del movimiento indígena; tal como lo manifiestan algunos registros fotográficos incluidos en artículos de la misma revista donde se alcanzan a ver algunos ejemplares pegados en sedes de organizaciones indígenas y campesinas. Más adelante se elaboraron nuevas versiones del afiche que fueron incluidas en el periódico Unidad Indígena como portada o como anexo para su difusión.

En 1975, meses después de la disolución del Grupo Taller 4 Rojo, Nirma Zárate y Diego Arango diseñaron el primero de varios carteles en torno a la figura de Luis Carlos Cárdenas, líder del sindicalismo independiente secuestrado y asesinado en Medellín por fuerzas armadas del estado colombiano en 1973, cuando ejercía como vicepresidente del Sindicato de Trabajadores Independientes de Antioquia, Sintradepartamento (CSPP, 1974). Realizados bajo el nombre de Taller Causa Roja, estos trabajos tienen unas cualidades visuales y gráficas diferentes, en parte por la elección limitada de colores apenas tres- para dar forma a la imagen: el negro para delinear algunas formas y las figuras, y el rojo describe fondos geométricos de color o se usa en la información tipográfica, sobre el blanco del soporte. Esta austeridad cromática redunda en una composición visual sobria pero contundente, donde la imagen del sindicalista se presenta de cuerpo completo y de perfil, con sus manos amarradas por detrás. Este diseño aparece en varios materiales de difusión, propaganda y apoyo de actividades sindicales y del Comité de Solidaridad de Presos Políticos y, como el de Mejía, fue distribuido en organizaciones sociales y sindicales, y particularmente en aquellas que se encontraban vinculadas al Comité de Solidaridad con los Presos Políticos.

Las coordenadas temporales entre la producción del primer y último cartel que mencionamos en este apartado dejan comprender aquel proceso de desvinculación paulatina de los integrantes del Grupo Taller 4 Rojo del campo del arte. No queda duda del impacto que algunos de ellos mantienen en la actualidad; en el caso particular del cartel dedicado a Cárdenas, gracias a la apropiación que terceros han hecho de aquel, se manifiesta en los ejemplares que aún penden de las paredes de la sede del Comité Solidaridad con los Presos Políticos en Bogotá -entidad de la cual es símbolo desde su fundación, y en las variaciones que se encuentran desde aquella época en las oficinas de la actual sede de la Escuela Nacional Sindical en Medellín. En suma, esta clase de estampas expresan el interés crítico y extensivo de circulación de los integrantes del Taller 4 Rojo y su campo circundante; son testimonios y documentos que dan cuenta de la lucha popular en un tiempo presente, y que 
con el transcurrir de los años operan una activación de la memoria que rebasa los temas y problemas propios del campo artístico.

\section{Sobre las pancartas y vallas/Alternativa}

La producción visual del grupo incluyó la producción de vallas que acompañaron operaciones de movilización y acciones directas emprendidas por algunos movimientos sociales. Este apoyo al movimiento popular se manifestó desde el principio de la década de 1970 a través de algunas iniciativas del movimiento campesino e indígena, en las que por ejemplo, Jorge Mora y Jorge Villegas estuvieron involucrados como equipo de diseño y diagramación de algunos libros publicados o impulsados por la Asociación Nacional de Usuarios Campesinos (ANUC) como El primer mandato campesino y plataforma ideológica. Modo de producción socialista (1970), Mandato Campesino (1972) y Primer mandato campesino, La tierra pa'l que la trabaja (1974).

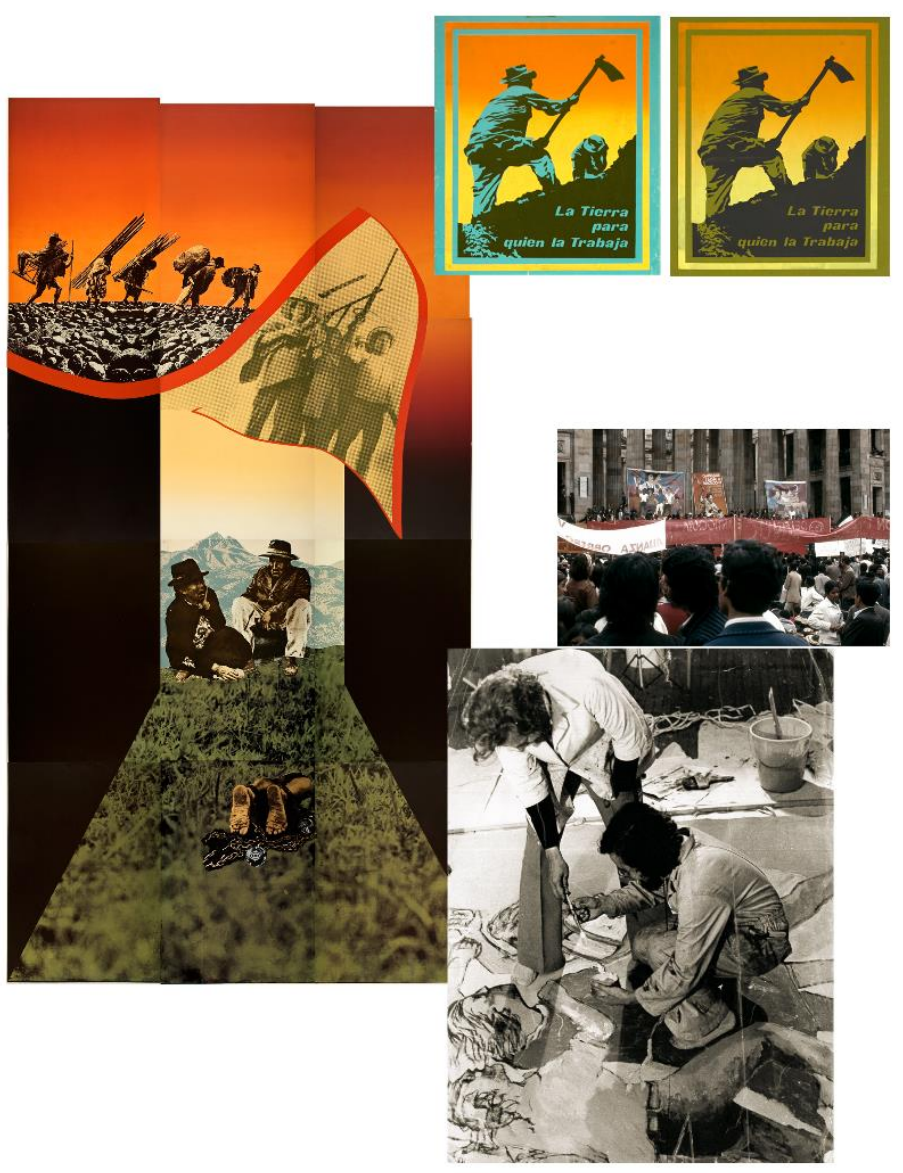

Fig. 4. Valla Colombia 72 (Diego Arango y Nirma Zárate / Grupo Taller 4 Rojo. Ca. 1972. Fotoserigrafía sobre papel, $400 \times 210 \mathrm{~cm}$ ), carteles dedicados a la lucha campesina (atribuido al Grupo Taller 4 Rojo. Ca. 1972. Serigrafía sobre papel, 28 x 21cm), Fabio Rodríguez Amaya y Carlos Granada trabajando en la ejecución de un aval pintada, y registro fotográfico de movilización en la Plaza de Bolívar en Bogotá con vallas realizadas en la plataforma del Taller 4 Rojo (1974) 
Una de las obras de mayor envergadura referidas al mundo campesino, elaborada con una exquisitez narrativa y técnica, muestra una genealogía del campesinado, su proceso de organización y resistencia: Colombia 1972. Allí se muestra la situación de explotación del campesinado desde la época colonial hasta el presente, pero al tiempo la manera en que se ha organizado para la lucha en el presente. Durante la investigación nos preguntamos sobre la circulación de esta pieza, pues su tamaño monumental de $400 \times 210$ metros (en 12 pliegos) implica toda una logística para su exhibición en cualquier lugar abierto o dentro de un recinto. Si bien no encontramos documentos de su uso en movilizaciones, varios de los integrantes del colectivo han declarado en entrevistas que se ubicó en algunas sedes de trabajo y reunión campesinos, así como su participación en marchas y movilizaciones. Otras propuestas visuales derivaron del acompañamiento del grupo al movimiento campesino de otras maneras; en primer lugar en procesos de formación, como lo indican unos carteles en serigrafía de pequeño formato (tamaño carta) y sin firma alguna que muestran la imagen clara de un par de campesinos en acciones de cultivo con una elocuente frase: "La tierra para quien la trabaja".

Otras creaciones visuales elaboradas por el Grupo Taller 4 Rojo, en apoyo a estas organizaciones sociales circularon en dispositivos como la revista Alternativa y el periódico Unidad Indígena, y describen un momento de tensión y discusión de origen ideológico, político y personal que desembocó en una fractura del grupo ampliado, pero continuó con otras conformaciones y proyectos colectivos. Giangrandi, Granada y Rodríguez Amaya continuaron como grupo y mantuvieron la denominación Taller 4 Rojo, mientras que Arango y Zárate crearon un nuevo grupo de trabajo llamado Taller Causa Roja. Ambos colectivos de manera independiente continuaron apoyando procesos populares, tal como lo indican los carteles impresos en litografía comercial (offset) que uno y otro produjo para convocar al 3er congreso de la Asociación Nacional de Usuarios Campesinos (ANUC) realizado en Bogotá en 1974.

Sin embargo, incluso después de la fragmentación del grupo, los artistas no se limitaron a diseñar materiales que narraban la lucha indígena y campesina vivas (libros de propaganda y afiches de convocatorias a encuentros y congresos) sino que el compromiso con estas organizaciones populares implicó la participación y apoyo a acciones directas: elaboraron pancartas y vallas en pintura que marcharon con las multitudes en algunas movilizaciones, las cuales por obvias razones no han sobrevivido hasta hoy. No obstante, nos quedan testimonios de la existencia de algunas de éstas a través de algunos registros fotográficos. Por ejemplo, Pedro Salamanca, amigo del grupo, registró parte del proceso de producción de una valla realizada para la marcha del 1 de mayo de 1974: se observa a Granada y Rodríguez Amaya con pincel en mano sobre el piso de un taller trabajando en la pintura en la que un grupo de jóvenes marchantes empuñan una de sus manos. De otro lado, Jorge Mora 
tomó fotos de algunas de estas pinturas-vallas en la movilización convocada durante al 3er Congreso de la ANUC, y cuyos bocetos encontramos, milagrosamente, en el repositorio personal de uno los integrantes y por lo mismo reconocimos como del grupo. En estas vallas se muestran alegorías del gremio trabajador junto a retratos de cuerpo entero de los protagonistas marchantes: obreros y campesinos de distinto género y diferentes edades, empuñando los utensilios de trabajo: azadones, machetes y hoces, acompañadas de consignas como "Viva la Unidad Campesina" o "Viva la Unidad Obrero-Campesina Popular". Después de una ardua pesquisa, fue sorprendente encontrar estas fotografías e identificar en ellas la trayectoria de estas pancartas: en una, la valla es sostenida por la multitud justo cuando pasa al lado de la Iglesia de San Francisco, sobre la carrera séptima, y en otra foto se observa izada delante del Capitolio Nacional, en el punto de llegada de esta clase de manifestaciones de la capital: la Plaza de Bolívar en el centro de Bogotá. Además, una de estas fotografías circuló en la contraportada de la revista Alternativa número 16, en la que se dedica un artículo extenso al 3er Congreso de la ANUC, institución de origen estatal, que fue tomada por los mismos usuarios campesinos ante la negligencia de los gobiernos de Lleras Restrepo y Misael Pastrana ante la promesa de una redistribución de tierras como parte de una reforma agraria efectiva (Rudqvist, 1983). Estas instancias de circulación de las pancartas, directamente empleadas en las marchas y a través de la documentación incluida en publicaciones independientes como Alternativa, dan cuenta del impacto que tuvo la producción visual y gráfica sobre la visualidad y formas de imaginación política de la lucha campesina y obrera de aquellos años.

\section{Coalición con sindicatos formación para la autorepresentación}

De acuerdo al horizonte del grupo Taller 4 Rojo, dispuesto a construir plataformas de formación, se propiciaron varios procesos de instrucción para la producción de imágenes destinadas a la autorrepresentación, semejantes al que derivó en los carteles de pequeño formato sobre el campesinado que mencionamos en el apartado anterior. Quizás uno de los trabajos de acompañamiento más comprometido fue el que realizaron Arango y Zárate, como Taller Causa Roja, con algunos procesos de lucha obrera y sindical.

En primer lugar, destaca el apoyo que dieron, junto a otros activistas, a la huelga de la textilera Vanitex en Bogotá, una de las más largas de 1976 en Colombia, y que significó un proceso de formación de las partes: la de los mismos trabajadores huelguistas, pero también la de los artistas y activistas que le acompañaron. En principio, los últimos empezaron a apoyar la huelga, e iniciaron algunas actividades de formación de derechos sindicales, y pronto llegó el momento de producción mancomunada de materiales gráficos y visuales que expresaban e impulsaban la lucha. Uno de los afiches de mayor circulación es uno en el que se muestra a una joven familia de medio cuerpo

Revista do Programa de Pós-graduação em Arte da UIS Vol.15, n²/julho-dezembro de 2016 Brasília
ISSN-1518-5494 ISSN (versão eletrônica):2447-2484 
en pie de lucha, en el que se destaca la mujer, una madre joven y resuelta con un brazalete que la identifica como trabajadora de Vanitex, mientras carga a su hijo de brazos, acompañada y apoyada por su compañero. Esta representación da justicia al papel que tuvieron las mujeres huelguistas, mayoría entre los trabajadores de la empresa, y por supuesto el apoyo que las familias hicieron a esta protesta. Esta imagen circuló independientemente en variaciones cromáticas y pronto se convirtió en una imagen icónica de la huelga, pues circuló en la revista Alternativa (1976) y luego sirvió de imagen de portada al documento que recogió la experiencia de la huelga, incluyendo las dificultades que vivieron los trabajadores, quienes luego de negociar y trazar acuerdos con las directivas de Vanitex fueron traicionados: algunos líderes de la huelga fueron paulatinamente despedidos de la empresa sin justa causa y luego la empresa se declaró en quiebra para poder despedir a todos los empleados y así evitar más protestas (Sánchez, 2009: 258 y ss). Ese documento titulado Huelga. Huelga Carretel Vanitex-1976 (1978) recoge una experiencia que buscaba aportar a otras agremiaciones sindicales, señalando los logros así como los errores desde una perspectiva constructiva, con el fin de enseñar y enriquecer las luchas de otras organizaciones y sindicatos contemporáneos.

Un par de años después de la huelga de Vanitex Diego Arango y, especialmente, Nirma Zárate emprendieron un trabajo de apoyo y de formación para la autorepresentación de algunos sectores sindicales. Impartieron talleres de formación en instituciones comprometidas con la consolidación del sindicalismo radical, independiente y alternativo, como el Instituto Nacional Sindical (INS) y la Escuela Nacional Sindical (ENS). Entre los sindicatos de líderes de esta línea estaba Sintradepartamento, sindicato de los trabajadores públicos de Antioquia, que se declaraba independiente de las centrales obreras, y de los partidos políticos, e impulsó un Sindicalismo Independiente y Clasista (Escuela Nacional Sindical, ENS, 2011). Cuando Sintradepartamento construyó su sede en Medellín en 1977, encargaron a Zárate la realización de un mural ${ }^{10}$ en el auditorio que lleva como nombre Luis Carlos Cárdenas; allí se representó la fuerza histórica y contemporánea del movimiento popular en Colombia situado en la geografía antioqueña: lideran la marcha el propio Cárdenas junto a María Cano y Camilo Torres, y tras ellos un amplio grupo de líderes y mártires de la lucha popular que participan del repertorio visual elaborado por el Taller 4 Rojo.

${ }^{10}$ En esta labor Zárate contó con la colaboración de Felipe Larrea, Alexis Forero y Teresa Quiñones, tal como señala la firma en el mural hoy día. 


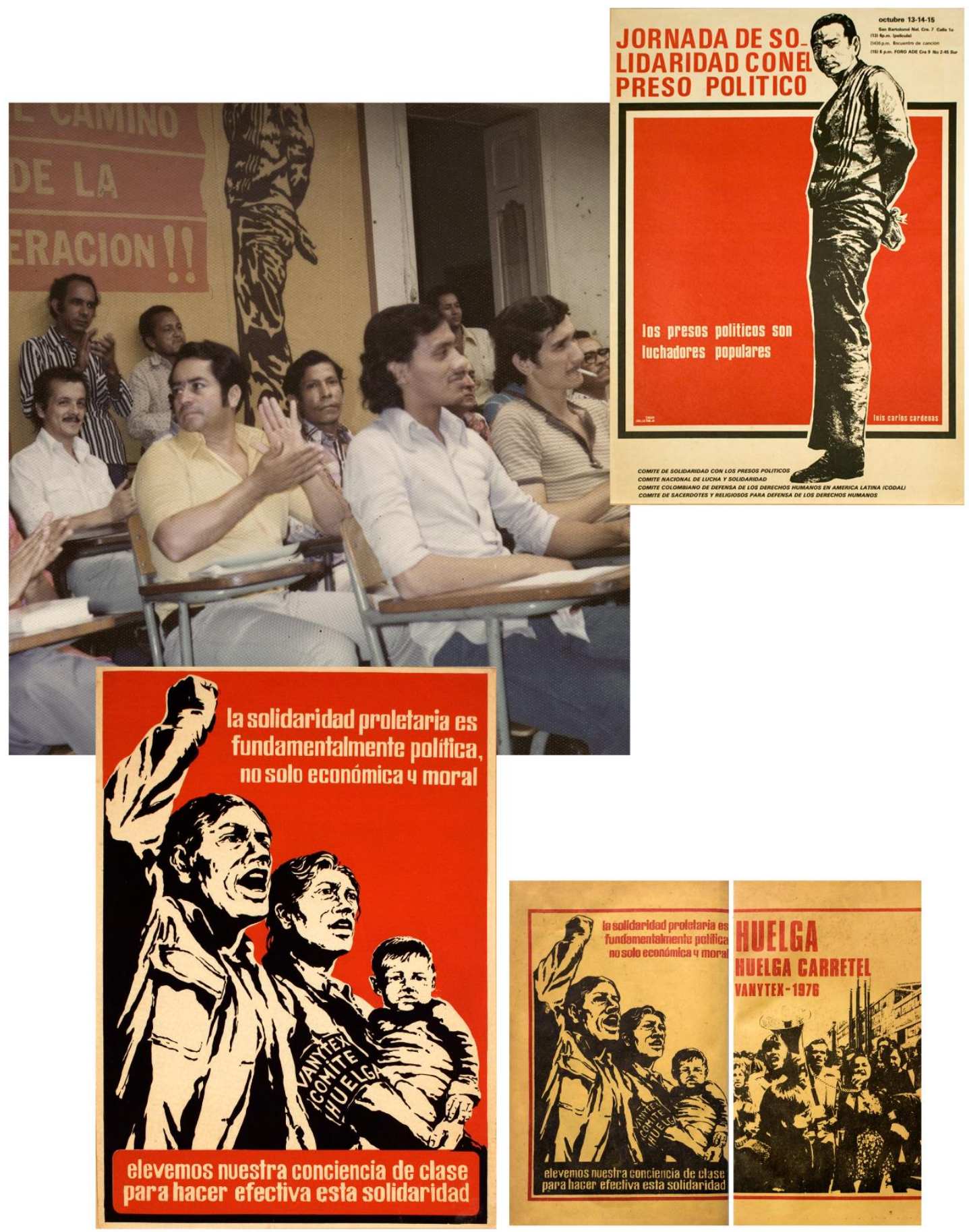

Fig. 5. Fotografía de reunión en la antigua sede de Sintradepartamento (ca. 1978), cartel de difusión del Taller Causa Roja (Diego Arango y Nirma Zárate) sobre la Jornada de Solidaridad con el Preso Político (1976), cartel de difusión del Taller Causa Roja (Diego Arango y Nirma Zárate) sobre la huelga de la textilera Vanitex, y portada y contraportada del Boletín Huelga. Huelga Carretel - 1976 (1978) 
Zárate lideró también algunos talleres de serigrafía para la elaboración de materiales de difusión y propaganda de las actividades de movilización y de encuentros de varios sindicatos y federaciones sindicalistas. Aún quedan de esa actividad algunos ejemplares, y otros resultantes de los aprendices de Zárate y Arango, es decir, de estudiantes de sus aprendices. En el archivo del INS de Bogotá, por ejemplo, encontramos varios de estos carteles que anuncian actividades entre 1980 y 1985, convocadas por agremiaciones sindicales como Fenasintrap, Fanasibancol, Sintrapopular, Sintrabanca, Fedetrol y Sintrabendeficiencia, entre otros, y en muchos se pueden reconocer con relativa facilidad fuentes visuales y matrices semejantes a las usadas en estampas del Taller 4 Rojo, Taller Causa Roja e incluso en revistas como Alternativa y Unidad Indígena. El mural y estas estampas dan cuenta de la extensión de la producción del Taller 4 Rojo, y del horizonte de ampliación de los usos de la gráfica más allá del campo artístico y la manera de insertarse en la realidad y vida de las organizaciones sociales para participar activamente en sus prácticas y acciones cotidianas.

Como anticipamos en la introducción, la producción artística del Grupo Taller 4 Rojo resulta visible en los relatos producidos por la Historia del arte en Colombia, de hecho, es relativamente fácil rastrear la circulación de estas imágenes en exposiciones, bienales y premios del campo del arte. Sin embargo, aunque tales relatos advierten sobre la vinculación del taller a otros campos de trabajo derivados de la acción de movimientos sociales, son pocos los estudios que particularizan la producción visual, la circulación o rol de las imágenes destinadas a tal fin; consideramos que este horizonte de circulación y producción visual es posiblemente el lugar en donde más claramente se manifestaron las convicciones y expectativas políticas del grupo, de allí la importancia de explorar los campos de circulación otorgada a la producción sostenida desde la plataforma del Taller 4 Rojo, pues es a través de estas acciones de circulación y extensión que los procesos creativos generados desde el grupo tornaron en prácticas políticas activas.

\section{Referencias}

ARANGO, C.. El auge del grabado contestatario en los años sesenta y setenta. Ministerio de Cultura. Bogotá, 2002.

BARÓN, M.S., y Ordoñez R., C. Plataformas de producción para la historia del arte colombiana. De la historia del arte colombiano de Salvat al Instituto de Investigaciones Estéticas y viceversa (1971-1984), 2015. Disponible en: https://www.youtube.com/watch?v=gXdRnaFbAy4. 
BARÓN, M.S.; ORDOÑEZ R., C.. Rojo y más Rojo. Taller 4 Rojo; producción gráfica y acción directa. Bogotá: Fundación Gilberto Alzate Avendaño, 2015.

BERMÚDEZ, R. J.. La imagen constante. El cartel cubano del siglo XX. La Habana: Editorial Letras, 2000.

BUCHLOH, B.. "De la Faktura a la Factografía". Formalismo e historicidad: modelos y métodos en el arte del siglo XX. Madrid: Akal Ediciones, 2004.

CASA DE LAS AMÉRICAS. Encuentro de Plástica Latinoamericana. La Habana: Casa de las Américas, 1972.

ESCUELA NACIONAL SINDICAL. "Sintradepartamento, bastión histórico de la lucha del sindicalismo independientes" 25 de agosto, 2011. Disponible en: http://www.ens.org.co/apc-aa-

files/4e7bc24bf4203c2a12902f078ba45224/08 22 2011.pdf [Sept 1 de 2013].

GAMBOA, A.. El Taller 4 Rojo. Entre la práctica artística y la lucha social. Bogotá: Secretaría Distrital de Cultura, Recreación y Deporte. Bogotá, 2011.

ROJAS, J.M.. Sobre el compromiso del investigador social. Fundación Rosa Luxemburgo, 2015. Disponible en: http://rosaluxspba.org/es/sobre-el-compromiso/ [Mayo 1 de 2016]

RUBIANO, G. "La figuración política" en Historia del Arte Colombiano. Bogotá: Editorial Salvat, 1983..

RUDQVIST, A.. "La organización campesina y la izquierda. Anuc en Colombia 19701980". Universidad de Uppsala, 1983. Disponible en: http://documents.mx/documents/la-organizacion-campesina-y-la-izquierda-anuc-encolombia-1970-1980.html [Mayo 1 de 2016]

S.A., Llamamiento al proletariado, las masas del pueblo en general, y a los intelectuales y trabajadores de la cultura y de la plástica. Sin editar, ca. 1973.

SÁNCHEZ A., R..Huelga! Luchas de la clase trabajadora en Colombia, 1975-1981. Bogotá: Universidad Nacional de Colombia, 2009.

VIVES I P., R.. Guía para la clasificación de grabados. Madrid: Arco Libros, 2003.

W.AA.. Huelga Carretel Vanitex- 1976. Bogotá: En Marcha, 1978.

Artigo recebido em maio de 2016. Aprovado em julho de 2016 